\section{THE "PATENT MEDICINE" AND NOSTRUM EVILS.}

J. M. ANDERS, M.D., LL.D.

Professor of Medicine and Clinical Medicine in the Medico-Chirurgical College.

PHILADELPHIA.

Encouraged by a small measure of success resulting from the efforts put forth in the recent past to stamp out the "patent medicine" and secret nostrum evils, it behooves the medical profession at large to forward the beneficent effects of an awakening that has come none too early, until victory for reputable therapeutics and pharmacy is no longer in doubt. PIndividual members of our profession and medical organizations can aid the progress of this praiseworthy work by a calm, temperate, dispassionate discussion of the question, more particularly by pointing out the reasons for the phenomenal success of these doubtful preparations and by urging measures of relief in the interests of the public and professional weal. It is the province of the trained and disinterested physician to give appropriate and efficient direction to the movement.

\section{THE NATURL OF THE BUSINISS.}

It is well known that adulterants are extensively introduced into foodstuffs and medicines. This vicious practice is not of recent birth, but has long been carried on by the orientals. Such adulterations and falsifications have been gradually brought under the control of state and municipal authorities, but an even greater American curse has been allowed to grow and develop, without official molestation by a patient and long-suffering people-the "patent medicine" and nostrum enterprises.

It is well to recollect at the outset that a patented medicine is not a secret medicine, since the inventor or manufacturer must disclose the composition and also the process of manufacture; this information is obtainable on application to the patent office of the government. It is, however, protected for a given time, 17 years, after which period it becomes public property. On the other hand, the trade-mark nostrum, under which head come innumerable secret or semi-secret proprietary preparations, is a perpetual monopoly, and to this class belong so-called "patent medicines," which, however, have not been patented. Since the nostrums would have narrow chances of success without the patronage of physicians, and since also so-called "patent medicines" are supported principally by the general public, it seems to me that a divisional study of the subject based on this significant distinction is necessary.

The lay press, more especially such representative publications as Collier's Weekly, Ladies' Home Journal, and others, have already broken soil in the field of "patent medicines," and their efforts promise the richest harvest; they are fully entitled to the warmest gratitude of the medical profession, as well as of all who are truly desirous of promoting the social good.

To attempt to point out to a medical audience the capabilities for harmful effects of the many known "patent medicines" which are used by a confiding public would be a work of supererogation. Physicians also know that exorbitant charges are made for these preparations-a fact not yet realized by the general public. Indeed, the extent of the prostitution of talent and services to the injury of their fellow-men, by the venal manufacturers of these preparations, strikes one with painful astonishment. Numerous individual instances could be cited to corroborate this statement, but it is enough here to refer specifically to peruna, which has been exploited by its quack owner as a certain cure for catarrh-a term so defined as to embrace nearly all human ills. The composition of this much-advertised preparation, according to analyses carried out by Collier's Weekly, is as follows: One-half pint Cologne spirits, 190 proof, and $11 / 2$ pints of water, adding thereto a little cubebs for flavor and a little burned sugar for color. But peruna has many conspicuous rivals, and it is an intercsting fact that, taking the different "patent medicines" at random, it will be found that alcohol in some form is, as a rule, the principal constituent.

Mr. Edward Bok has done telling pionecr work in creating public sentiment against the patent-medicine curse, and has catalogued a long list of preparations by name, giving the percentages of alcohol which each contains.

A glance at this list will convince the most skeptical that the percentage of alcohol contained in the various "bitters" and "bracers" is, on the average, higher than in spirituous and malt liquors, or the products of the saloon. It is a matter of observation that in places (e. g.,prohibition states) in which whisky can not be purchased the consumption of patent medicines reaches its maximum. It would appear, therefore, that they have been conceived, manufactured and used quite outside of the sphere of legitimate medicine.

The principal objection to these nostrums, however, appertains to the well-known methods which have been and are adopted to exploit them. With an assumed derotion to mankind, which is only equalled by the love of the Tudor monarchs for flowers and gardens, and an implied burning desire to relieve suffering humanity from its manifold ills, attractive representations are made to the public, through advertisements, which, however, can be readily shown to be largely fictitious.

Unfortunately, the people of the work-a-day world, who are afflicted with chronic ailments of various kinds and degrees, whatever their mental training, are unconsciously credulous in the matter of the extravagant claims made in the newspapers and magazines by the vendors of "patent medicines." Moreover, the modern type of quack is quite able to appeal with success to the most cultured classes of society, so well has he or his hired advertisement writer mastered the art of seduction.

Females complaining of backache, and young men and boys, who believe what they read in newspapers and magazines about the meaning of their meaningless symptoms, become ready victims of a vicious class of swindlers. It appears to me. lowever, that many loubtful or so-called borderland nostrums, which are advertised in both the medical and lay press as being of great value in incurable conditions and readily prescribed by practicing physicians, are not less objectionable than the "patent medicines." At all events, thev are scarcely accessible to the spirit of science. Obviously the present propaganda against the evil under consideration must be extended beyond the "patent medicines" to many well-known "proprietary" articles."

Again, the testimonials of widely-known persons, many of whom have attained to eminence in their respective callings, have stimulated and encouraged the use of nostrums. Here is a shining example: Mrs. Leslie Carter says of peruna: "It cures all catarrhal affections like magic. No money could tempt me to be

1. Journal A. M. A., Sept. 23, 1905. 
without this remedy for eren a day." The columns of our newspapers and other lay periodicals as advertising media have been the principal or essential element in bringing about the pecuniary success of "patent medicines." While wo need not stop to inquire what has been the motive or moral principle governing the universal aetion of the lay press in respect to its advertising pages in the past, it has manifested an obrious ambition for a quick financial return, to say the least. There is cause for exultation, however, in the fact that a wave of righteous public indignation has appeared on the horizon and bids fair to sweep over and extirpate the free field so long pre-empted by the quacks of this country.

Mr. Samuel Hopkins Adams has made the profession and public alike his debtor by giving a "full explanation and exposure of patent-medicine methods and the harm done to the innocent public by this industry." He has pointed out a number of great practical truths which can scarcely be over-emphasized. In the first place, as is well known to physicians, the long-continued use of certain .drugs (c. g., cocain, opium, arterial stimulants) will most certainly enslave the devotees to their use, and thus are the ranks of the drug fiend constantly recruited. Mr. Adams clearly echoes medical opinion in pointing out that the alcohol-laden "bitters," "sarsaparillas," and "tonics," taken daily and in increasing loses, make not for health, but for disease. Such information as this writer has been giving directly to the public will prove effective in lessening the annual outlay of moners by Americans for medicines having little or no ralue for the conditions in which they are employed.

Having considered "patent medicines," I shall attompt to point out the reasons for a parallel demand for proprietary remedies and nostrums. At the outset, the fact is to be emphasized that it would be unjust to condemn all proprietary preparations; they are not objectionable provided that their composition be revealed and they are judiciously and honestly exploited. On the other hand, proprietary remedies that are secret or semisecret in character, and the immense majority of the "proprietaries" belong to this category, are clearly condemnable. Every intelligent and properly-minded plyysician must concede that it is wholly unscientific to prescribe remedies of whose composition he is ignorant, or a mixture for whose reliability he can not vouch, and no one can deny that the medical profession has been a powerful and unfailing adjunct of the manufacturers of this class of remedies; they have been allowing the manufacturers of secret proprietary articles to compound their preparations and even to point out the indications for their use. Again, as Dr. Frank Billings ${ }^{2}$ says, "many so-called medical journals are subsidized by medical manufacturers, and one-half of the medical journals of the country would be out of existence if it were not for the nostrum advertisements."

One of the most unfortunate aspects of the situation is the widespread control exercised by the Proprietary Association of America over both the medical and lay press. Moreover, the advertisements of the "proprictaries," be it observed, exhibit in a striking degree the same structure and method as those of "patent medicines," and they, together with the visiting agents, are chiefly responsible for the extensive employment of nostrums by overcredulous practicing physicians. In this connection, the claims of certain writers that the flagrant iniquities of many pharmaceutical manufacturers are

2. "The Nostrum Evil," Tre Jocrsir A. M. A., Dec. 2, 1905. the natural result of modern therapeutic nihilism must be largely admitted. As elsewhere stated, "Our colleges of medicine and pharmacy are scarcely alive to the moral responsibility involved in this gravely threatening evil. The teachings of these schools should be of such a character as to enable students to discriminate between genuine and spurious remedial agents."

The principal neglect on the part of the medical schools affects the science and art of pharmacy, and on this question the editor of American Medicine, in a recent issue, pertinently remarks: "The revolt against these nauseating mixtures of the past generation of physicians was, in part at least, a cause for that remarkable stampede toward homeopathy which this country witnessed. All the work of discovering proper methods of administering drugs has thus been left to the pharmacist. The tendency toward therapeutic nihilism would certainly have become a great evil but for the pharmacist, to whom the medical profession certainly owes a great debt of gratitude."

Unquestionably, the time is ripe for the inauguration of a campaign of education among physicians and college faculties in the interests of legitimate, scientific therapentics and pharmacy.

\section{IIOW TO COMBAT THE BUSINESS.}

I shall next deal with various measures and methods for the cure of the nostrum evils. In the first place, a most timely organized effort has been instituted by the American Medical Association, with the object of exposing the evils of the preparations under discussion, of determining their precise composition, and showing the extent of the harmful effects which they produce. To 'T'HE Journal of the American Medical Association belongs the credit of suggesting the formation of a board of control, with the double object of reviewing all medical preparations offered for insertion in the advertising pages of that journal, and of giving a description of the unoffieial preparations, which conform to the required standard, the whole to be issued in a work supplementary to the United States Pharmacopeia, to be entitled, "New and Unofficial Remedies."

Furthermore, the board of trustees of the American Medical Association has authorized the creation of a Council on Pharmacy and Chemistry, which proposes to examine into the composition of the numerous and varied preparations that are constantly offered to the medical profession independently of the United States Pharmacopeia. Up to the present time the investigations have been confined principally to proprietary nostrums, on which the editor of THE Journal of the American Medical Association has wisely commented as follows: "Before we can proclaim war on patent medicines with energy and a clear conscience, it will be necessary for us as physicians to rid ourselves of the proprietary nostrum evil by ceasing to prescribe preparations that are nothing more nor less than patent medicines. Before medical journals can criticize newspapers for carrying patent medicine advertisements, they must themselves refuse advertisements of similar preparations, even though these be dignified with the name of proprietary medicines."

It should be stated here that the secretary of agriculture has organized in the Bureau of Chemistry of that department a drug laboratory for the investigation of the purity, adulteration, false labeling and false brand-

3. Anders: "The Curriculum of the Scientific Professional College," the Medical Bulletin, October, 1905. 
Ing of drugs. 'This laboratory, which was established about two and a half years ago, has accomplished much valuable work, and the bulletins issued from it can be secured by addressing a request to that effect to the sceretary of agriculture. More recently, the agricultural department, at the request of the postmaster-gencral, has investigated certain secret remedies and nostrums, as well as the advertisements offered for transmission through the mails. As a consequence, the literature pertaining to the nostrums investigated has been excluded from the mails, and to this extent the public has been protected against fraudulent allegations.

In commenting on the important work undertaken by the postoffice and agricultural departments at Washington, Dr. W. H. Wiley remarks: "In the interests of the medical profession, of the pharmaceutical profession and of the public, it is hoped that federal control of drugs in general may become universal and more efficient. In this way the interests of the two great professions mentioned, and of the public, can be best conserved." As measures of relief for the evils under consideration, the combined results of the labors of the lay press, the medical press, the Council on Pharmacy and Chemistry of the American Medical Association, and the two departments of the United States government mentioned above, can not be overestimated, and through these channels loth the general public and the medical profession are receiving reliable, impartial intoruation on the subject.

In attempting to deal with this great problem, however, its financial aspects must be reckoned with, since men engaged in this nefarious business pay annually enormous sums of money to newspapers, magazines and medical periodicals for cunningly executed advertisements of a deceptive character. It has been estimated that the yearly amount expended for "patent medicines" and other nostrums exceds $\$ 100,000,000$ - "more than one thousand dollars to each daily, weekly and monthly periodical in the country." The query, Can the mutualIv profitable financial relations existing between the iress and the patent-medicine makers be severed? is pertinent. A few high-class secular periodicals, c. g. The Outlook, The Evening Post, Life, Collier's Weekly, and The Ladies' Home Journal, refuse to accept such advertisements, thus showing an ardent desire to break $u p$ this illicit combination. We may be assured that a thorough appreciation of the beneficial results to the public resulting from this attitude of the lay press will prove to be an incentive for emulation, and that eventually, as the result of the upheaval in progress, all reputable publications-both medical and lay--will be lifted to the same high, ethical level.

On the other hand, to my mind, the great American evil could be more effectually remedied by a comprehensive legal enactment compelling all makers of proprietary articles to place the formula on the bottle. Legislation could be of further service by insisting that preparations containing poisons must be labelled accordingly, while those containing alcohol must give its precise percentage. Under these circumstances, laudatory adrertisements would no longer suffice, for the simplicity of their composition and the absurdity of the extravagant and unfounded claims made for them as therapeutic agents would be known to the general public. Such legislative action has been taken both in the state of Torth Dakota and by the New Zealand parliament.

4. The Jovrxal A. M. A., Dec. 3, 1004.
According to Dr. Syme, ${ }^{5}$ there followed in the lastnamed country a storm of protest by the manufacturers of. "patent medicines" and their agents, which led to a modification of the regulations to the extent that the formula was to be lodged with the Health Department. But the manufacturers still objected and they decided not to send their medicines to New Zealand, realizing, as this writer observes, that "they would have no demand at the extravagant prices at which they had hitherto been sold."

The patent medicine manufacturer is quite aware of the fact that so soon as the public shall have been made acquainted with the composition of his fraudulent preparations popular support will be promptly withdrawn. It is, however, impossible to foresee the time when state legislative action shall have progressed to the point of acconplishing the coveted practical good, owing to the existence of organized opposing forces, such as the Proprietary Association of America, and other influences. Meanwhile it seems to me that the work of educating the people at large devolves naturally on physicians and pharmacists (although up to the present undertaken principally by the lay press), even at the risk of being denounced as actuated by self-interest.

It is of the utmost importance to make the public understand, as the result of the present crusade, that the "demonstrations of popular sentiment" in favor of these nostrums are absolutely fictitious, that they are inspired by the unwarranted claims of the manufacturers, and that adrertising contracts exercise a controlling influence over the lay press, especially in the rural districts. The popularizing of such information would at least compel manufacturers to guard and moderate the unfounded claims of their patented and proprietary articles. May we not indulge ourselves in the hope that a properly directed, energetic and unceasing agitation of the sul)ject, in the absence of efficient protective legislation, may compel the adoption of the habit of placing the formulas on the bottle?

As touching the secret proprictary articles, which are advertised principally in the medical journals, it is assuredly the province of our profession to create an appropriate professional sentiment, and to disseminate thoughts and data, that will bring medical men in touch with those influences that make for a higher moral and ethical standard. No other factor would be so influential as an uplifting force in this prodigious task as the united medical press. THE JoURNAI of the American Medical Association has had the courage and independence to give to the medical profession of this country the true situation regarding the nostrum evil in a truly scientific spirit, and is rapidly eliminating the advertisements of articles of an objectionable character from its adrertising columns. As stated above, a certain number of high-class lay journals are refusing to accept the adrertisements of unethical "patent medicines." and the question naturally arises, Can the best medical journals afford to occupy any longer a lower ground with reference to the secret proprietary articles? A movement of this sort should include the education and enlightenment of the general public-a course that would, in turn, give greater scope and meaning to all professional sentiments and lines of action. So long as the community is opposed, or even indifferent, to the endeavors of the profession to correct the abuses under discussion, just so long will the deep-rooted inclination of the populace to

5. International Medical Tournal of Australasia, quoted by The Jorriat, A. M. A., Nov. 4, 1905. p. 1422. 
disregard or even combat new ideas and methods defeat our best efforts.

Finally, the profession must adopt a general plan of action if it would hope to execute a winning fight against the great wrong, and I would respectfully submit a series of lines of attack to be included in such a plan:

1. Agitation through co-operative effort on the part of high-class journals, medical writers and medical organizations with a view to enlightening the profession and elevating the standard of the profession.

2. The enlightenment of the public by the agencies noted under 1 with the aid of the influential lay press, which has aiready rendered excellent pioneer service.

3. Medical schools and medical journals should aim to educate physicians regarding official preparations and proprietary articles whose composition is known and of proved usefulness.

4. The proper training of medical students in the science and art of pharmacy, including prescription writing.

5. Co-operative effort on the part of physicians and scientific pharmacists is to be encouraged, e. g., such as the admirable work that is being carried out by the Council on Pharmacy and Chemistry of the American Medical Association.

6. Continued exposure of "patent medicine" and nostrum methods and the disclosure of the composition of these preparations by the lay and medical press (to the public) is urgently needed.

7. The creation of a professional sentiment to the effect that trade-marked nostrums are unworthy of being prescribed.

8. Attempts to emancipate a shackled medical and lay press must be persistently maintained.

9. The enactment of appropriate legislation-a line of action in which it will be hard to demonstrate practical results in the immediate future, owing to powerful organized opposition.

10. The furtherance of the aims of the upheaval in progress by completing the organization of the merlical profession of America in accordance with the plan proposed by the American Medical Association in 1900.

\section{SODIUM AURATE: A NON-IRRITATING LOCAL ANTISEPTIC OF REMARKABLE POWER.*}

F. H. VERHOFFF, A.M., M.D.

Pathologist and Assistant Ophthalmic Surgeon, Massachusetts Charitable Fye and Ear Infirmary. BOSTON.

The need of an antiseptic combining effective germicidal power with lack of toxicity to the tissues is well known. So many chemical antiseptics have been tried without success that the belief has become prevalent that no chemical substance could possibly fill these requirements. In fact, attention has been directed of late almost exclusively to the development of serum therapy, which, however, has yielded but few practical results. The problem has presented itself to me particularly in connection with gonorrheal opthalmia. Here it would seem easy to overcome the infection by means of local applications, yet thus far no satisfactory antiseptic has been available for this purpose. After many failures in attempts to solve this problem, I believe I have found an antiseptic which will prove of great value not only in the treatment of infections of the eye, but also in the

* Read before the New England Ophthalmological Society, and before the Boston Society of the Medical Sciences. treatment of many other conditions in which the use of a local antiseptic is indicated. In this communication the method of preparing the antiseptic will be given and the experiments which demonstrate its bactericidal properties will be described. While in the cases in which it has been tried it has given most gratifying results, as yet these are necessarily few in number, and a full report of its action in a series of clinical cases must be deferred.

\section{PREPARATION.}

The antiseptic is prepared as follows:

One gram (15 grs.) of gold ehlorid ${ }^{1}$ is dissolved in 50 c.e. distilled water. To this is cautiously added sufficient of a 5 per cent. aqueous solution of sodium hydrate to produce a faintly alkaline reaction with ordinary litmus paper. As the process of neutralization approaches the stage desired the fluid becomes lighter in eolor and also slightly turbid. One hundred c.c. of a 1 per cent. solution of boric acid is then quickly added and the whole thoroughly shaken. This should cause the turbidity to disappear and the fluid to turn somewhat darker in color. If the turbidity persists, it indicates that too much sodium hydrate has been added. The total volume should now be made up to 200 c.c. with normal saline solution, filtered and kept in a glass stoppered bottle. The final solution should give a faintly acid reaction. While, as will be shown, the gold does not exist in the fluid as a chlorid, for practical convenience the strength of the fluid is best expressed in the percentage of gold chlorid used in its preparation. The above solution will, therefore, be designated as a $1 / 2$ per cent. solution. A 2 per cent. solution may be prepared from which the lower percentages may be obtained by dilution, but it is much more difficult to arrive at the proper degree of acidity in the higher strength. By evaporating the fluid to dryness the antiseptic may be obtained in powder form from which an ointment can be prepared.

The bactericidal properties of this fluid are dependent on the presence of gold. It is the partial or complete meutralization of the fluid, however, that renders possible its use as a practical antiseptic. The boric acid is not an essential constituent and is added only to avoid a practical difficulty. This arises from the fact that in order to prevent precipitation the fluid must be sufficiently acid, while if too acid it is highly irritating to the cye. The boric acid neutralizes any slight excess of sodium hydrate and ensures an acid fluid free from irritating qualities. If, through mistake, too much sodium hydrate has been added and precipitation has taken place (which may not occur until after twenty-four hours) the precipitate can be dissolved by adding an excess of hydrochloric acid and the acidity again reduced to the proper degree by sodium hydrate. When properly prepared the solution remains stable indefinitely.

The chemical reactions which take place in the preparation of this fluid are assumed to be as follows:

$\mathrm{HAuCl}_{4}+\mathrm{NaOH}=\mathrm{NaAuCl}+\mathrm{H}_{2} \mathrm{O}$.

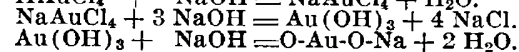

Further reaction is prevented by the boric acid, which reacts with the excess of sodium hydrate, thus-

$$
\mathrm{B}(\mathrm{OH})_{3}+3 \mathrm{NaOH}=\mathrm{B}(\mathrm{ONa})_{3}+3 \mathrm{H}_{2} \mathrm{O} \text {. }
$$

The final constituents of the fluid, then, are in all probability sodium aurate, sodium chlorid, sodium borate and boric acid. Of these it is obvious that the soclium aurate alone gives the bactericidal properties to the fluid. It is hardly necessary to state that the antiseptic could be prepared by the use of other compounds of gold and of other alkalies, but the method here given scems to be the most convenient.

1. Chlorld of gold may be obtained from wholesale druggists or from dealers in photographic supplies. Although sold under this name it is really hydrochlorauric acid, $\mathrm{HAuCl}_{4}$. The pharmacopelal preparation, chlorid of gold and sodium may be substituted if used in double quantity. It is, however, more expensive. 